Journal of Social Sciences 8 (1): 39-42, 2012

ISSN 1549-3652

(C) 2012 Science Publications

\title{
Firm Performance-A Social Networks Perspective
}

\author{
Jane Tung \\ Department of Marketing and Distribution Management, \\ Business Management School, Hsing Wu Institute of Technology, Taiwan
}

\begin{abstract}
Problem statement: The study aims to offer a discussion on social networks and their effect on firm performance and also to illustrate the ways by which the firms utilize social capital through networks. Approach: The literature review and arguments were conducted to provide a systematic discussion of social networks and their effects. Results: The study had provided with a detailed understanding of the strategies that had been found to be highly significant in successful organizational performance. The results of this discussion suggested that social networks affect firm performance in a positive manner and can contribute to sustainable competitive advantage. Conclusion: It confirms that building up of social networks for big and small firms provides valuable links and solves numerous issues which auger well for the companies and should be treated with great importance.
\end{abstract}

Key words: Social capital, social networks, network competence, product innovation, firm performance

\section{INTRODUCTION}

A sudden growth and expansion of social networks have led to an increasing interest in the study of the structure and the function of social networking sites and how they affect the functioning of the firms. A better understanding of social networks can help companies to predict economic outcomes and take strategic decisions. Social networks, in the form of online brand communities, with customers as members, allow the companies to interact with the customers and helps in the exchange of information thereby allowing companies to get a valuable feedback regarding its products and merchandise.

Firms also enter into collaborations for joint production and social commerce. In the field of product development the inter organization networks can be very effective for the joint discussion about the product (Mitsuhashi and Greve, 2009; Ansari et al., 2011). Many new and small firms have lack of resources for the development, mainly due to inexperience and a lack of goodwill. Thus as a way of competing and grabbing a foothold in such a scenario involves bootstrapping, which involves activities for securing funds and resources. By using social networks such companies can gather finances, by building up strong ties in the initial stages and later on weak ties as they grow big (Jones and Jayawarna, 2010).

Another important aspect which is emerging slowly is the concept of a local social capital where an individual who values more of his local contacts, even though he has global contacts. This is relevant mainly in case of local entrepreneurs. Thus according to scientists, people with more and better social capital will be able to realize their goals. Ranging from contracts to building goodwill and securing finances, social capital is the priority in all types of endeavors around the globe (Huang and Wang, 2011; Schutjens and Volker, 2010; Asadi et al., 2008). Social ties have been found to regulate exchanges through an informal and interpersonal way and they help to push back the limitations of a weak infrastructure, especially in the case of a financial crisis (Sheng et al., 2011).

The study is to provide several facts and discussions in relation to social networks and social capital and their effect on firm performance based on the following literature review. Propositions in regard to the use of social capital in organizations with respect to managerial decisions, resource reconfiguration, product innovation and firm performance are being continuously developed for achievement of organizational goals.

\section{MATERIALS AND METHODS}

Literature review and propositions development provide constructs in relation to social networks and firm performance.

Social networks: In the last decade, research has shown the importance of social capital in every aspect of life. Studies show that social capital is a valuable resource as compared the job being done and people who bring in more social capital into the work gain success more. Inter-firm relationships and connectedness via networking have grown and gained a 
substantial amount of attention in organizational research, strategy planning and marketing. Competing firms find themselves rooted to networks of social and professional relationships, which can be used for exchange of information. Companies are forced to join hands in the presence of short life cycles of products and increasing costs of research and development. The activities carried out among members in a network, when shared among them, affects the decision making for every firm. In this report we explore the various effects social network and social capital has on the overall firm performance. Matters concerning the utilization of networks by ESS firms and how networks can be advantageous over political decisions have been discussed. Social networking among the artists and people in general is used a form of marketing (Schutjens and Volker, 2010; Liang et al., 2010; Collins and Clark, 2003).

Marketing and social networks: Ansari et al. (2011), in their research tells us how marketers are becoming extremely intent on understanding the predictability and the connection of social networks. Social network data and actions offer various opportunities for research in the field of marketing. They reveal that connectivity with one aspect may lead to further connectivity to other aspects. Secondly, their research also points out that friendship, music downloads and communities show a kind of reciprocity. While networks can be huge, communities become a part of the network and become clusters within the network. A brief review of marketing and statistical literature regarding social networks reveals how it can be divided into two streams. The first one deals with results pertaining to word of mouth behavior and social interactions while the second deals with modeling on network structure. While the first is a common phenomenon, the latter is a rapidly developing concept helping organizations at large. Organizations performing in different industries and varied market environments have been found to be facilitated by marketing through social networks of the organization and helps managers to make strategic decisions towards achieving innovative products, technology and attaining competitive advantage.

Social networks and innovation: Developed countries have experienced a decline in the number of manufacturing countries. In lieu, the governments of these countries turn to foster innovation and in turn cluster initiatives to obtain prosperity and security of regions. It was seen from research that the network competence and network location were the key to better innovation and performance. Inter-firm connections are the channels of communication for the firms. Such collaborations can be of immense value to the firms. Degree of centrality is the extent to which a firm is central to the network, based on the number of links that join it with other firms in the network. The main advantages form such collaborations range from exchange of knowledge, which is very essential for innovation. Such links help in gathering complementary skills from other firms as innovation requires the combined use of several important factors. Also economies of scale emerge when more knowledge is received via large projects, which are always better than small projects. (Chiu, 2009) Network structure is seen as a core and a periphery. Firms in the centre are densely and more intensely linked to each other. Principal players which occupy the central region of this core drive many other smaller firms. The absence of a principal player would result in lesser connectedness for the lesser firms. In this report we will see how companies with high level of network competence are located centrally on the network (Chiu, 2009).

Social networks, bootstrapping and firm success: Bootstrapping is something every small firm has to resort to. A small firm when initially set up has no market reputation, goodwill and has limited resources. The resources are usually funds of the entrepreneur and loans from banks. For a firm to grow in business and profits, it has to capture the attention of the bigger companies. Social networks have been instrumental in creating a bridge between these small enterprises and the large ones. The small firms can avoid asymmetric information and responds to a change in the environment to a competitive scenario. Entrepreneurs who can use innovative techniques through social networks to gain resources are better able to survive and grow and gain the reputation. In this regard strong ties have been found to play more important roles than weak ties and at a newly established phase both strong and weak ties are preferred. The initial ties are termed as identity ties, based on already existing relationships with other social partners, they are very important for the new firm. For a later stage, however, weak ties based on purpose and function become more important. The study will discuss about the implications of social networks on fund securing.

Development of propositions: Benefits from marketing are directly related to social networks-the different researches conducted have clearly indicated how the benefits of marketing can be magnified by social networks. A study in the application of social networks in research and development of a firm reveals 
that social networks integrate several different model components to gain a multiplicity in the model. For research and development, the communication among professionals has been of major importance. Results of research have clearly indicated that different components of the network were needed for a hypothesis and the research concluded that multiple gains were involved in modeling relationships jointly. Thus, social networks have been obtained to be positively related to marketing decisions and their benefits and this proposition is constantly developing towards betterment of organizational performance (Ansari et al., 2011; Liang et al., 2010)

Social networks are positively related to network competence and product innovation-in search of determination of the innovation companies have looked into the company's previous endeavors and findings, technological competence and corporate culture. However with rising costs and shorter factory-to-market time, the firms have resorted to partnerships and tie ups for innovation concepts. Results show a positive relation between the firm's relationships with other firms and their innovation goals (Chiu, 2009). In network competence, which is the ability of a company to interact with its environment, the social networks have an impact on the firms' performance and gives considerable competitive advantage. Thus social networks have been instrumental in establishing network competence and have been constantly helping in the invention of new concepts and fostering innovation. Also the proximity to the core has been of great importance to all firms. Smaller firms have been resorting to partnerships to achieve a closer space to the core (Chiu, 2009).

Social networks have a positive influence on small firms and their quest for securing resources.

Research helps to understand that bootstrapping is indeed necessary for those from non established backgrounds. Research provides a positive outcome on firm performance due to bootstrapping activities through social networks. Strong ties help gather resources for friends and family and also enable joint utilization techniques, where they share equipments and labor. Weak ties on the other hand helped to gather resources on a regular basis once the relationships are established and reputation is made. It was also found that those who were able to find funding in the form of debt and equity continue to bootstrap on a regular basis (Jones and Jayawarna, 2010; Schutjens and Volker, 2010).

\section{RESULTS}

Different studies have thus reflected and supported the concerned topic on how social networks affect the firm performance. In accordance with the various results, network competence, location centrality, innovation and marketing have all been found to have a positive relation with networks. Different scholars have represented their views reflecting the importance of these aspects. The marketing part of the company thus relies heavily on the social networks to study client behavior and interact with them. Internal social networks provide the platform for internal discussions with individuals from different designations, thus helping them to reach an impetus. The bootstrapping of funds and the building of reputation has been of prime importance of these small companies and the social networks have been instrumental in establishing weak and strong ties.

\section{DISCUSSION}

The study has some limitations, namely the non availability of certain detailed data from enterprise firms, so our study was based on mainly secondary data relating to journals and articles (Schutjens and Volker, 2010). Also certain questions remain unanswered, like what the network members actually do that helps the firm to perform in a better way? How do the costs of getting resources decrease through a large network mainly comprising of big companies? More research on these need to be conducted o get a detailed analysis.

\section{REFERENCES}

Ansari, A., O. Koenigsberg and F. Stahl, 2011. Modeling multiple relationships in social Networks. J. Market. Res., 48: 713-728. DOI: 10.1509/jmkr.48.4.713

Asadi, A., M. Akbari, H.S. Fami, H. Iravani and F. Rostami et al., 2008. Poverty alleviation and sustainable development: The role of social capital. J. Soc. Sci., 4: 202-215. DOI: 10.3844/jssp.2008.202.215

Chiu, Y.T.H., 2009. How network competence and network location influence innovation performance. J. Bus. Ind. Mark., 24: 46-55. DOI: 10.1108/08858620910923694

Collins, C.J. and K.D. Clark, 2003. Strategic human resource practices, top management team social networks and firm performance: the role of human resource practices in creating organizational competitive advantage. Acad. Manage. J., 46: 740751.

Huang, K.P. and K.Y. Wang, 2011. How Guanxi relates to social capital? A psychological perspective. J. Soc. Sci., 7: 120-126. DOI: 10.3844/jssp.2011.120.126 
Jones, O. and D. Jayawarna, 2010. Resourcing new businesses: social networks, bootstrapping and firm performance. Venture Capital, 12: 127-152. DOI: 10.1080/13691061003658886

Liang, X., H.A. Ndofor, R. Priem and J. Picken, 2010. Top management team communication networks, environmental uncertainty and organizational performance: A contingency view. J. Managerial Issues.

Mitsuhashi, H. and H.R. Greve, 2009. A matching theory of alliance formation and organizational success: Complementarity and compatibility. Acad. Manage. J., 52: 975-995.
Schutjens, V. and B. Volker, 2010. Space and social capital: the degree of locality in entrepreneurs' contacts and its consequences for firm success. Eur. Plann. Stud., 18: 941-963. DOI: 10.1080/09654311003701480

Sheng, S., K.Z. Zhou and J.J. Li, 2011. The effects of business and political ties on firm performance: Evidence from China. J. Marketing, 75: 1-15. DOI: 10.1509/jmkg.75.1.1 